\title{
Analisis Retorika Visual Konten Iklan Produk Pada Account Instagram Bank BNI
}

\author{
Sonson Nurusholih \\ Desain Komunikasi Visual, Telkom University \\ Jl. Telekomunikasi No. 1, Dayeuh Kolot, Jawa Barat 40257 \\ email: sonson@telkomuniveristy.ac.id
}

Received: 25 April 19

Revised: 4 Oktober 2019

Accepted: 7 Oktober 2019

\begin{abstract}
Abstrak: Sebagai media yang dirasa cukup efektif dalam menyampaikan pesan, foto banyak digunakan para produsen untuk menyampaikan informasi dan cara berkomunikasi dengan konsumen. Salah satunya yaitu yang dilakukan oleh Bank BNI yang menggunakan foto sebagai sarana menyampaikan informasi dan komunikasi dalam kegiatan promosinya. Fokus masalah yang akan diteliti dengan kegiatan promosi dari Bank BNI adalah pesan visual yang ada dalam setiap promosi iklan kreatifnya yang menggunakan gaya pesan retorika di mana pesan yang ingin disampaikan tidak secara eksplisit sebagaimana umumnya foto produk komersial. Penelitian ini bertujuan untuk menganalisis serta mendeskripsikan pesan retorika visual apa yang ditampilkan pada beberapa konten yang disampaikan dalam account Instagram Bank BNI. Untuk teorinya, penulis menggunakan teori retorika visual dari Sonja K. Foss, dan untuk menganalisisnya digunakan analisis semiotika Barthes. Sementara untuk metode penelitiannya, digunakan metode kualitatif dengan pengambaran secara deskritif. Hasil analisis pada setiap kegiatan konten Bank BNI di Instagram, ditemukan visual yang muncul adalah foto-foto yang tidak eksplisit berhubungan langsung dengan pesan promosi yang ingin disampaikan.
\end{abstract}

Kata kunci: Iklan Media Sosial, Instagram Bank BNI, Retorika Visual, Semiotika Barthes

\begin{abstract}
As the media that is considered quite effective in conveying messages, photos are widely used by producers to convey information and to communicate with consumers. One of samples is what has been done by Bank Negara Indonesia (BNI) which uses photos as a means of conveying information and communication in its promotional activities. The focus of the problem to be investigated with promotional activities from BNI is the visual message in every creative ad campaign that uses a rhetorical message style where the message to be conveyed is not explicitly like most commercial product photos. This study aims to analyze and describe what visual rhetorical messages are displayed on some of the content delivered in BNI Instagram accounts. For his theory, the author uses the theory of visual rhetoric from Sonja K. Foss, and to analyze it uses Barthes's semiotic analysis. As for the research method, qualitative method is used with descriptive descriptions. The results of the analysis on each of BNI's content activities on Instagram, it is found that the visuals appeared are photographs that are not explicitly directly related to the promotional message that is to be conveyed.
\end{abstract}

Keywords: Social Media Ads, Instagram Bank BNI, Visual Rhetoric, Barthes Semiotics 


\section{PENDAHULUAN}

Iklan pada saat ini, hakikatnya secara umum, sehari-hari sudah menjadi bagian dari kehidupan masyarakat. Dimulai pagi hari ketika konsumen mulai bangun tidur hingga malam dan kembali tidur lagi senantiasa disuguhi dengan iklan. Pagi hari sebelum aktifitas, ketika masyarakat menyalakan televisi maka berbagai iklan sudah muncul di layar. Begitu juga ketika orang-orang melakukan perjalanan ke sekolah atau ke kantor, di jalan-jalan terpampang iklan media cetak dan setelah sampai tempat kerja, ketika pekerja membuka komputer atau laptop dan menyambungkannya dengan internet maka muncul pop up yang berisi iklan. Oleh karena itu iklan menjadi hal yang sangat dekat dengan masyarakat, suka atau tidak suka orang-orang tidak bisa menghindarkan berbagai hal itu. Sejak kehadiran internet, banyak produsen merubah strategi pemasarannya, dari media cetak ke media digital.

Perkembangan internet di Indonesia seperti halnya di seluruh dunia penggunanya menunjukkan peningkatan yang sangat pesat. Saat ini fenomena yang sedang diperbincangkan adalah internet marketing yang merupakan sarana komunikasi pemasaran yang tepat untuk digunakan pada abad ini. Dari berbagai riset terungkap bahwa pengguna internet di Indonesia perkembangan rataratanya meningkat sebesar 3 juta pada 10 tahun terakhir ini. Seiring dengan pertumbuhan pengguna internet di Indonesia ini, layanan belanja online tercatat sebagai bentuk aktifitas yang terus melesat perkembangan penggunanya. Beberapa platform jejaring sosial dibuat dan muncul untuk melayani kebutuhan penggunanya, hadir lebih awal pada masa berkembangnya internet seperti Yahoo Messenger, LINE, Whatsapp serta beberapa situs web seperti Facebook, Twiter hadir dengan beragam fitur yang popular seperti layanan berbagi foto, video serta fitur lainnya hingga yang sedang marak saat ini adalah aplikasi jejaring sosial dengan fitur utamanya berbagi foto dan video yaitu Instagram. Aplikasi ini sedang naik daun karena kelebihan fungsinya yang bisa berbagi foto dengan beragam fitur 
menarik seperti pengguna dapat mengambil foto kemudian dapat mengedit sesuka mungkin dengan filter digital yang ada pada aplikasi ini dan kemudian berbagi kepada siapa saja yang ada dalam jaringannya atau ke media sosial lainnya seperti Facebook, Twitter bahkan ke blog atau sebuah situs.

Saat ini masalahnya, fungsi Instagram tidak saja sebagai tempat untuk berbagi foto keluarga, teman atau siapapun, namun telah bergeser menjadi media pemasaran suatu bisnis, bahkan saat ini di Indonesia dengan konten bisnis yang menjual atau mempromosikan produknya jumlahnya mencapai jutaan account yang menunjukkan bahwa Instagram menjadi media sosial yang sangat diperhitungkan dalam promosi sebuah bisnis. Hal ini diperkuat oleh survei yang dilakukan WeAreSocial.net dan Hootsuite, yang menyebutkan pada saat ini Instagram menjadi platform media sosial dengan jumlah pengguna berada pada posisi ke tujuh terbanyak di dunia. Hingga pada Juni 2018, total pengguna Instagram telah mencapai angka lebih dari 1 miliar, dengan pengguna pasif terbesar berasal dari Amerika sebesar 110 juta pengguna disusul Brasil (57 juta) serta di urutan ketiga adalah Indonesia dengan pengguna sebanyak 53 juta. Instagram sendiri di Indonesia menjadi media paling sering digunakan keempat setelah Youtube, Facebook serta Whatsapp. Angka ini muncul karena selain sebagai jejaring sosial berbagi foto, konten pada Instagram juga diganti dengan produk bisnis.

Bank BNI adalah salah satu pelopor beriklan di media on-line yang mengusung strategi kreatif yang berbeda dari kebanyakan strategi kreatif yang diterapkan oleh pembuat iklan terkait dengan media Instagram. Hingga kini berdasarkan pengamatan penulis pada account Instagram BNI, sudah lebih dari 3000 foto dengan format iklan yang sudah diunggah dengan setiap unggahan bisa mencapai 600-1000 like dan ratusan komentar. 


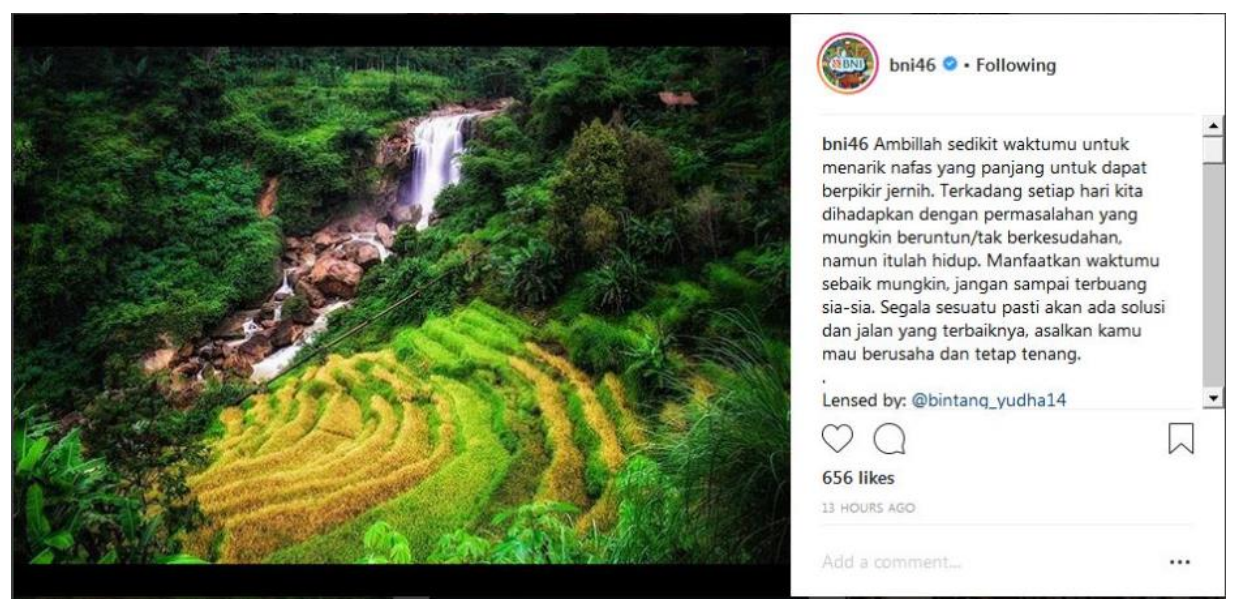

Gambar 1 : Tampilan Instragram Bank BNI Sumber : https://www.instagram.com/bni46/

Pada iklan yang bermediakan Instagram ini (Gambar 1), Bank BNI tidak banyak menggunakan kalimat/ copy yang panjang, alih-alih menampilkan warna yang menarik yang sarat dengan materi promosi, visual yang nampak adalah foto yang tidak ada hubungannya dengan pesan namun diberi caption yang cukup panjang. Akan tetapi walaupun kalimatnya tidak panjang, namun kontennya selalu dipenuhi dengan tanda-tanda visual yang penuh makna. Pada sebuah iklan terdapat unsur-unsur yang saling mendukung guna pesan yang diusung dapat tersampaikan dan dimengerti oleh target audience. Unsur-unsur tersebut di antaranya head words, color, music, picture, seen words, movement. Periklanan sendiri merupakan salah satu jenis komunikasi pemasaran yang mengacu pada teknik komunikasi yang banyak digunakan para pemasar untuk menjangkau target audiensnya (konsumen) dalam upaya menyampaikan pesannya (Moriarty, 2011:11). Penggunaan media sosial sebagai media promosi sangat menarik untuk diteliti, karena secara medium, sebetulnya Instagram sebagai tempat berbagi foto dan video, namun dalam prakteknya banyak dimanfaatkan oleh para produsen untuk mempromosikan produknya. Pada account Instagram Bank BNI, hampir 
seluruh unggahannnya menampilkan beragam foto yang isinya tidak berhubungan langsung dengan produk yang ditawarkan namun dengan menggunakan unsur retorika atau bujukan halus dengan menampilkan beragam benda-benda yang diasosiasikan atau berhubungan dengan produk yang dijual.

Adapun penelitian ini bertujuan untuk mengetahui makna atau simbolsimbol dari benda-benda yang ada dalam beberapa foto unggahan di Instagram Bank BNI dilihat dari perspektif teori retorika visual dengan menggunakan teori semiotika untuk memahami isi visualnya.

Dari hasil melalui penelusuran kajian pustaka, ditemukan beberapa penelitian sejenis yang menggunakan retorika visual sebagai analisisnya. Salah satunya penelitian berjudul "Analisis Retorika Visual Pada Iklan A Mild Versi Manimal" oleh Bergas Adhi Wijaya (2016), dimana penelitian ini mengupas masalah yang ditampilkan pada scene yang ada pada iklan A Mild Versi Manimal yang memilki alur cerita yang berbeda-beda yaitu mengenai perilaku manusia pada masyarakat urban di Indonesia (Wijaya, 2016 : h 1). Penelitian ini menggunakan teori retorika visual Sonja. K. Foss dan segitiga retorik milik Hesford dan Brueggemann dengan penggambaran bahwa retorika visual adalah istilah untuk penggambaran atau deskripsi studi mengenai citra visual dalam disiplin ilmu retorika. Menurut Douglas Ehninger (dalam Wijaya, $2016:$ h 1), retorika visual dapat mempengaruhi pemikiran dan perilaku masing-masing individu melalui stretegi penggunaan simbol dalam gambar. Sederhananya, retorika visual adalah bagaimana atau mengapa gambar visual memiliki makna dan arti.

Penelitian sejenis yang mengunakan retorika sebagai alat untuk menganalisisnya adalah penelitian yang dilakukan oleh Meli Agustin (2014) yaitu "Analisis Retorika Pada Iklan Vespa Berbahasa Jerman". Hasil penelitian ditemukan bahwa prinsip retorika pada iklan Vespa tersebut membantu penggambaran ide visual yang disampaikan sekaligus mempersuasi pembaca untuk membeli atau menggunakan vespa (Agustin, 2014). 
Peneliti lain yaitu Oktavianus Djoka Hutapea (2015), mengunakan teori retorika visual dalam penelitiannya yang berjudul "Retorika Visual Dalam Karya Fotografi di Instagram (Analisis Pada 30 Jenis Foto Di Instagram)". Dalam penelitiannya Hutapea (2015) menemukan bahwa dalam 30 foto di Instagram yang menjadi objek penelitian mengandung pola retorika visual berupa aksi simbolik, intervensi manusia, serta kehadiran pendengar.

Selanjutnya penelitian yang dilakukan oleh Hafid Kurniawan (2015), mengenai Efektivitas media Sosial Instagram Sebagai Media promosi Batik Solo "Inasinul". Hasil dari penelitian tersebut menunjukkan bahwa media sosial khususnya Instagram ternyata cukup efektif dalam menstimulasi perhatian audiens, utamanya meningkatkan pengetahuan kepada audiens akan produk yang ditawarkan, serta mengubah sikap audiens dari tahap yang hanya memperhatikan (attention) menjadi tahap untuk tertarik (interest).

Dari kajian penelitian di atas, umumnya penelitian tersebut menggunakan retorika visual sebagai alat untuk menganalisis objek-objeknya, namun dalam prosesnya objek yang diteliti tersebut tidak membahas mengenai pemaknaan visual. Untuk itu yang menjadi kebaharuan pada penelitian ini yaitu dengan membahas pemaknaan dari setiap visual dengan mengintrepretasikan setiap objeknya melalui pemaknaan teori semiotika.

\section{METODE PENELITIAN}

Penelitian mengenai analisis retorika visual ini menggunakan metode kualitatif yang memungkinkan peneliti untuk menginterpretasikan dan mendeskripsikan pesan dalam retorika visual yang disampaikan dalam iklan promosi produk Bank BNI. Peneliti menggunakan pendekatan semiotika dalam menggali makna dari pesan visual dalam iklan promosi produk Bank BNI yang meliputi visualisasi di media online yang merupakan salah satu strategi kreatif periklanan yang dibuat oleh tim kreatif kegiatan promosi Bank BNI. Penelitian ini 
juga berfokus pada pemaknaan pesan yang ada dalam iklan promosi produk Bank BNI yang dalamnya terdapat unsur retorika visual pada beberapa konten yang telah tayang di media online Instagram. Sumber data primer dalam penelitian ini berupa berupa screen shoot promosi produk Bank BNI di media online Instagram dengan konten yang diunggah adalah visual dengan teknik foto yang didukung dengan tambahan berupa caption. Mengingat banyaknya konten yang diunggah maka untuk penelitian ini konten yang akan dianalisis adalah foto (visual) yang disertai narasi (copy) dengan objek promosi kartu debit dan kartu kredit Bank BNI. Untuk data penunjang (sekunder) bersumber dari penelitian terdahulu guna mendukung data primer tersebut, juga untuk menggali lebih dalam analisis pada iklan promosi produk Bank BNI.

Dalam penelitian ini penulis menggunakan teori retorika visual Sonja K. Foss, yaitu penerapan retorika visual yang meliputi artefak komunikasi dan perspektif retorika visual, bukan retorika visual gaya bahasa seperti majas metafora, hiperbolis dan lain-lain. Adapun pengunaan teori ini adalah dengan menerapkan tiga karakteristik dalam artefak komunikasi yaitu aksi simbolik, intervensi manusia serta kehadiran audiens (Foss, 2004, hal. 303-313). Sementara untuk mengungkapkan makna yang tersirat dalam setiap visual digunakan analisis Semiotika Barthes. Untuk metode penelitiannya, digunakan metode kualitatif dengan pengambaran secara deskritif. Untuk mendapatkan data penelitian, peneliti melakukan triangulasi data yaitu dengan cara upaya memahami data dengan penelusuran berbagai sumber, narasumber, cara serta waktu (Ratna, 2010:241).

Data diperoleh melalui studi pustaka, pengamatan langsung pada konten promosi produk Bank BNI, khususnya pada tanda-tanda visual serta hubungan dengan pesan dalam narasi. Teknik analisis data yang akan digunakan yaitu data yang diperoleh kemudian direduksi ke dalam pola-pola tertentu, lalu dilakukan kategorisasi, kemudian menginterpretasi kategori-kategori tersebut berdasarkan 
skema-skema yang didapat kemudian diinterpretasikan, kemudian dapat diambil kesimpulan. Dengan kata lain data penelitian disajikan (data display) dengan menggunakan metode matriks untuk melihat tanda-tanda visual serta hubungan dengan pesan dalam narasi dalam iklan promosi produk Bank BNI sebelum akhirnya semua fenomena yang terlihat disimpulkan (conclusion drawing/ verification) atau diverifikasi.

\section{HASIL DAN DISKUSI}

Semiotika adalah ilmu yang mengkaji tentang tanda, baik itu pengertian simbol, indeks dan ikon. Dalam perkembangannya muncul gagasan mengenai makna detonasi dan konotasi yang dikemukakan oleh Roland Barthes dalam buku semiotik karangannya yang berjudul Image-Music-Text. Barthes membagi semiotika menjadi dua tingkatan pertandaan, pertama tingkat detonasi dan kedua pertanda konotasi. Detonasi adalah makna sebenarnya dari sebuah benda atau objek sesuai dengan makna sebenarnya, sedangkan konotasi kebalikannya adalah makna yang tidak sebenarnya atau makna ganda yang muncul dari pengalaman personal atau kultural (Barthes, 1984:13).

Detonasi berhubungan erat dengan penanda dan petanda pada realitas dimana tingkat pertandaannya menjelaskan hubungan antar keduanya yang menghasilkan makna eksplisit, langsung serta pasti. Sementara konotasi kebalikannya, dimana hubungan penanda dan pertanda di tingkat pertandaan mengandung makna yng tidak langsung (tidak eksplisit) serta tidak pasti. Seperti analisis Spradley yang menjelaskan bahwa makna detonasi diliputi oleh hal-hal yang diperlihatkan dengan kata-kata (makna referensial), serta teori konotasi ini juga menerangkan bahwa makna konotosi (Spradley, 1997:122).

Sumbo Tinarbuko mengilustrasikan contoh konotasi orang dengan gambar wajah tersenyum bisa saja diartikan sebagai suatu bentuk keramahan atau kebahagian, namun tersenyum bisa juga suatu ekspresi penghinaan terhadap 
seseorang, sehingga untuk memahami konteks suatu konotasi perlu unsur lain juga yang harus dipahami (Tinarbuko, 2009:20). Hal ini sesuai dalam teori yang diungkapkan Roland Barthes dalam munculnya sebuah makna denotasi pada peta tanda yang dibuat Roland Barthes dapat dijelaskan dengan uraian sederhana bahwa penanda dan juga petanda sangat mempengaruhi makna detonasi tersebut. Hal ini dapat dinyatakan bahwa sebuah tanda detonasi berpengaruh atau dapat membuat persepsi baru pada penanda konotasi. Seperti yang dikatakan Sobur misalnya kata "bunga mawar", persepsi yang akan muncul dari kata ini adalah bisa menjadi cinta, kasih sayang, kelembutan bahkan romantik. Hal ini bisa terjadi karena ada kesepakatan terdahulu mengenai makna yang terungkap dari masyarakat tertentu (Sobur, 2006:69).

Proses analisis retorika visual pada konten yang ada di account instagram Bank BNI adalah dengan mengobservasi jumlah seluruh konten yang tayang yaitu kurun waktu Oktober - Desember 2018. Adapun pembahasan objek visual yang dianalisis sebanyak empat konten yang mewakili konten lainnya. Tahap pertama dari analisis visual dalam konten di Instagram adalah dengan membuat matrik serta membedah visual melalui pendekatan semiotika Barthes dengan uraian berikut:

Tabel 1. Analisis Visual Dengan Pendekatan Semiotika Barthes

\begin{tabular}{|l|l|l|l|}
\hline No & Foto & Tanda Detonasi & Makna Konotasi \\
\hline 1 & $\begin{array}{l}\text { Tanda detonasi pada visual } \\
\text { di samping ini adalah: } \\
\text { Secangkir kopi, Head Set, } \\
\text { Gitar, Gadget, Flyer BNI } \\
\text { serta Kartu Kredit BNI. }\end{array}$ & $\begin{array}{l}\text { Gambar Secangkir kopi, Head } \\
\text { Set, Gitar, Gadget, Flyer Info } \\
\text { Acara Jazz BNI serta Kartu } \\
\text { Kredit BNI menunjukan pesan } \\
\text { tawaran menonton acara JAZZ } \\
\text { dengan diskon jika } \\
\text { menggunakan kartu kredit BNI. }\end{array}$ \\
\hline
\end{tabular}




\begin{tabular}{|c|c|c|c|}
\hline 2 & 1 & $\begin{array}{l}\text { Tanda detonasi pada visual } \\
\text { di samping ini adalah: } \\
\text { Kompas, Bintang Laut, } \\
\text { Kacamata, Paspor, Pesawat } \\
\text { Terbang, Perahu Kertas } \\
\text { serta Topi Anyam. }\end{array}$ & $\begin{array}{l}\text { Gambar Kompas, Bintang Laut, } \\
\text { Kacamata, Paspor, Pesawat } \\
\text { terbang, Perahu Kertas, Topi } \\
\text { Anyam menunjukan pesan } \\
\text { tawaran pergi liburan dengan } \\
\text { diskon jika menggunakan kartu } \\
\text { kredit BNI. }\end{array}$ \\
\hline 3 & & $\begin{array}{l}\text { Tanda detonasi pada visual } \\
\text { di samping ini adalah: } \\
\text { Kacamata Hitam, Kartu } \\
\text { Kredit BNI, Popcorn serta } \\
\text { Smartphone }\end{array}$ & $\begin{array}{l}\text { Gambar kacamata hitam, } \\
\text { popcorn, gadget serta kartu } \\
\text { kredit menunjukan pesan } \\
\text { tawaran menonton film } \\
\text { bioskop dengan diskon jika } \\
\text { menggunakan kartu kredit BNI }\end{array}$ \\
\hline 4 & 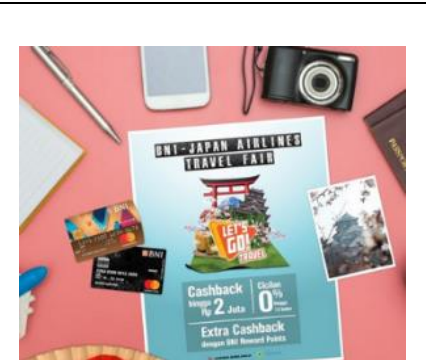 & $\begin{array}{l}\text { Tanda detonasi pada visual } \\
\text { di samping ini adalah: Kartu } \\
\text { Kredit BNI, Kartu Debit BNI, } \\
\text { Note + Pulpen, Gadget, } \\
\text { Kamera, Foto Kastil \& } \\
\text { Sakura, Kipas khas Jepang, } \\
\text { Paspor serta Pesawat }\end{array}$ & $\begin{array}{l}\text { Gambar notes, pulpen, gadget, } \\
\text { kamera, paspor, kapal jika } \\
\text { digabungkan dengan gambar } \\
\text { foto berisi kastil dan bunga } \\
\text { serta diperkuat dengan kipas } \\
\text { khas Jepang menunjukkan } \\
\text { pesan rencana perjalanan libur } \\
\text { ke Jepang }\end{array}$ \\
\hline
\end{tabular}

Dari uraian matrik di atas, kemudian setiap konten kembali dianalisis dengan teori retorika visual dimana sebuah gambar dapat dikatakan sebagai retorika visual jika memiliki tiga karakteristik yaitu gambar harus memiliki tandatanda simbolik, adanya keterlibatan manusia, serta penyajian visual diperuntukkan kepada audiens dengan tujuan berkomunikasi. Tanda simbolik pada konten visual dianalisis dengan semiotika Barthes seperti matrik di atas, intervensi manusia diperlihatkan pada objek-objek yang merupakan gambar yang sehari-hari dipergunakan oleh manusia, serta penyajian kepada audiens diperlihatkan melalui media Instagram. 
Adapun pembahasan analisis retorika visual diuraikan sebagai berikut:

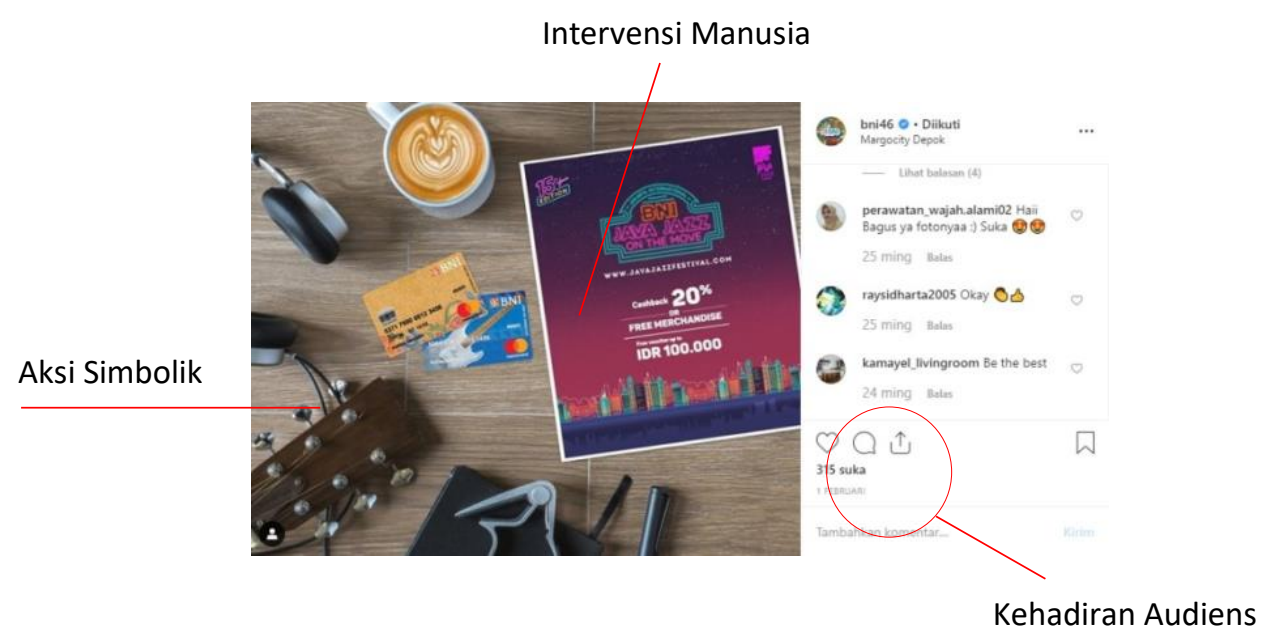

Gambar 2 : Unggahan Instragram Bank BNI

Sumber : https://www.instagram.com/bni46/

Pada gambar 2, memperlihatkan tanda visual yang merupakan aksi simbolik berupa cangkir kopi, head set, gitar, smartphone, flyer bank BNI serta kartu kredit BNI. Objek-objek tersebut secara detonasi memiliki makna sebenarnya, secara konotasi jika seluruh objek itu melalui intervensi manusia (desainer) masuk dalam satu visual maka menjadikan satu objek dan objek lainnya menjadi saling berhubungan. Cangkir kopi dimaknai sebagai hidangan untuk dinikmati, head set dan gitar berkonotasi musik serta smartphone dan flyer adalah media komunikasi. Jika dihubungkan maka pesan dari visual ini adalah Bank BNI mengajak konsumen untuk menikmasti acara musik (pesan dalam flyer) dengan penggunaan kartu kredit atau kartu debit Bank BNI sebagai alat bayarnya. Kehadiran audiens disini ditandai dengan respon dari pemirsa yang melihat unggahan ini sebanyak 315 tanda suka. 


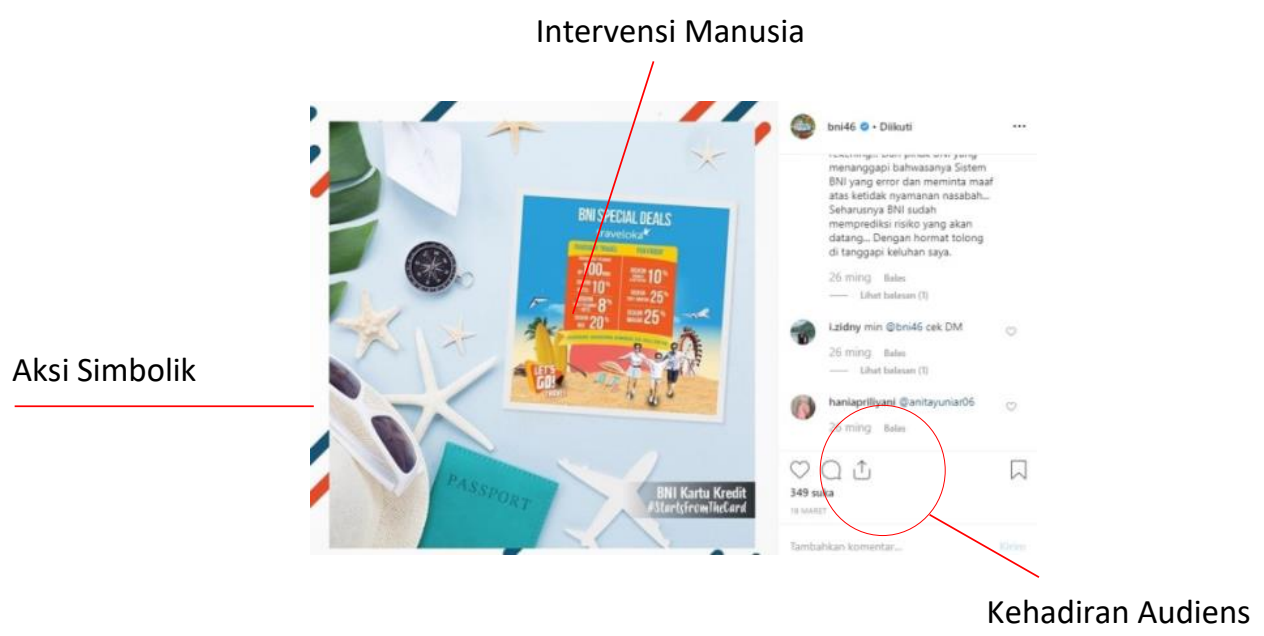

Gambar 3 : Unggahan Instragram Bank BNI

Sumber : https://www.instagram.com/bni46/

Sementara pada gambar 3, yang merupakan aksi simboliknya adalah tanda visual berupa kompas, bintang laut, kacamata, paspor, pesawat terbang, perahu kertas, topi anyam. Secara konotasi objek-objek tersebut merupakan objek yang berkaitan dengan tanda-tanda yang berkaitan dengan liburan, maka pesan dari visual konten ini melalui intervensi manusia (desainer) dengan tataletak sedemikian rupa adalah desain promo tawaran untuk pergi liburan dengan diskon jika menggunakan kartu kredit atau kartu debit bank BNI. Kehadiran audiens disini ditandai dengan respon dari pemirsa yang melihat unggahan ini sebanyak 349 tanda suka.

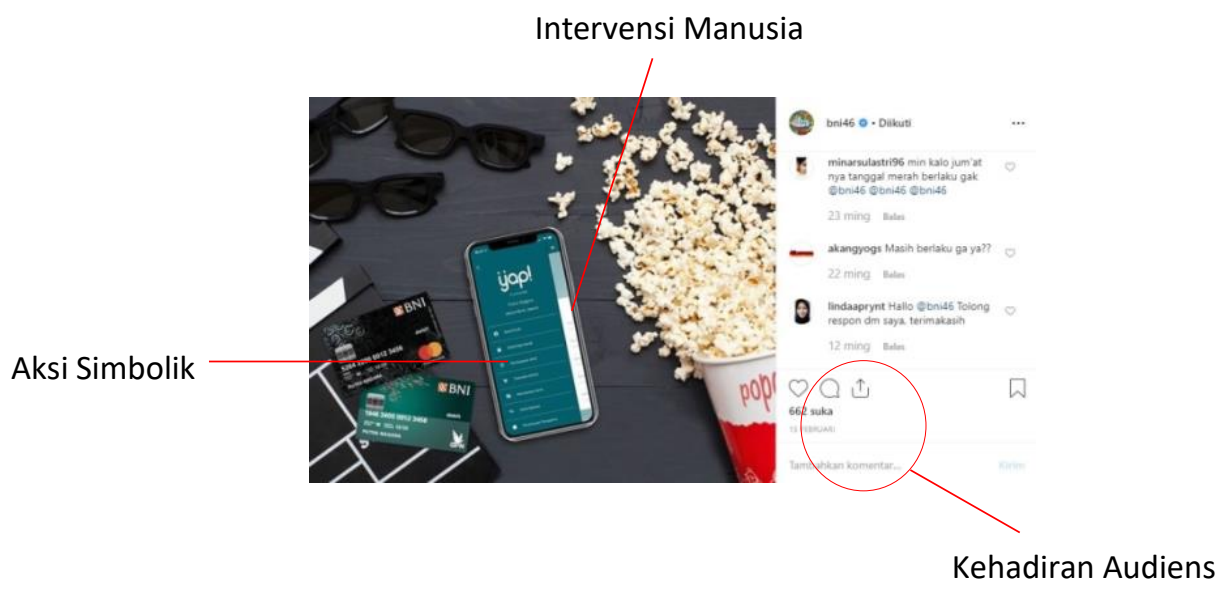

Gambar 4 : Unggahan Instragram Bank BNI

Sumber : https://www.instagram.com/bni46/ 
Pada gambar 4, yang merupakan aksi simboliknya adalah tanda visual berupa kacamata hitam, kartu kredit BNI, popcorn, smartphone. Popcorn secara detonasi adalah kudapan yang sering digunakan orang saat menonton sebuah acara seperti film. Dalam gambar diperlihatan popcorn disandingkan dengan smartphone yang memperlihatkan adanya jadwal film bioskop. Jika dihubungkan antara popcorn, informasi diskon menonton di bioskop maka visual pada konten ini melalui intervensi manusia (desainer) adalah tawaran menonton di bisokop dengan diskon jika menggunakan kartu kredit atau kartu debit bank BNI. Kehadiran audiens disini ditandai dengan respon dari pemirsa yang melihat unggahan ini sebanyak 662 tanda suka.

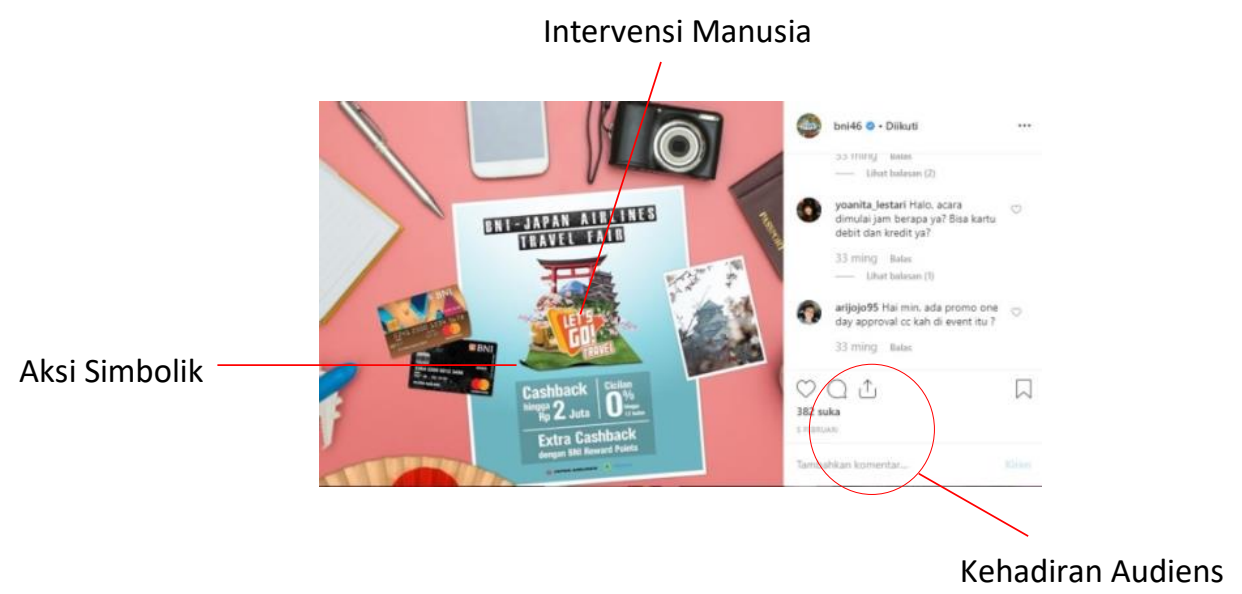

Gambar 5 : Unggahan Instragram Bank BNI

Sumber : https://www.instagram.com/bni46/

Pada gambar 5, yang merupakan aksi simboliknya adalah tanda visual berupa kartu kredit BNI, kartu debit BNI, note dan pulpen, smartphone, kamera, foto bergambar kastil dan bunga sakura, kipas khas Jepang, paspor serta mainan pesawat. Korelasi atau hubungan seluruh objek dalam visual tersebut melalui intervensi manusia (desainer) adalah tawaran kepada konsumen jika ingin berlibur ke Jepang akan mendapat harga diskon jika menggunakan kartu kredit atau kartu 
debit bank BNI. Kehadiran audiens disini ditandai dengan respon dari pemirsa yang melihat unggahan ini sebanyak 382 tanda suka.

\section{KESIMPULAN}

Sesuai dengan tujuan dari penelitian ini yaitu untuk mengetahui makna atau simbol-simbol dari benda-benda yang ada dalam beberapa foto unggahan di Instagram Bank BNI. Hasil analisis mengenai konten visual Bank BNI yang ada pada account Instagram Bank BNI menunjukkan bahwa untuk menjalin komunikasi pihak Bank BNI dengan konsumen, umumnya objek yang diunggah berisi konten dengan pendekatan persuasi. Dengan kata lain, pemilihan objek pada setiap konten ini merupakan aksi simbolik yang dipilih dan disusun melalui intervensi manusia (dalam hal ini desainer) maka objek tersebut dikaitkan dengan makna sebenarnya (detonasi). Namun dengan pemilihan objek yang disesuaikan dengan caption maka ketika digabungkan, menjadikan konten tersebut memiliki makna baru yang bersifat persuasi, di mana setiap visual yang dibuat tidak memasukkan unsur-unsur yang bersifat emosional atau menyentuh perasaan.

Setiap objek pada gambar selalu saling berhubungan dan berkaitan. Semua objek memiliki tanda masing-masing (detonasi), namun ketika disandingkan, visual yang muncul memiliki makna lain (konotasi). Tujuannya adalah para konsumen dapat memahami konten tersebut tanpa ada makna visual yang bersayap, hal ini ditandai dengan kehadiran audiens melalui tanda suka. Hasil analisis dengan retorika visual di mana setiap objek pada konten visual Bank BNI memiliki memiliki tanda-tanda simbolik, ada intervensi dalam pengaturan tataletak objeknya, serta konten visual tersebut disajikan pada sebuah media. Sehingga jelas, menjawab tujuan peneltian ini diketahui bahwa di setiap foto, aset benda-benda yang ada merupakan representatif yang digambarkan dengan simbol beragam benda-benda (retorika visual) merupakan bujukan halus produsen agar konsumen mau membeli produk yang ditawarkan. 
Selanjutnya penggunaaan analisis dengan retorika visual ini masih ada kekurangan yaitu ketiadaan dalam mendalami makna tulisan pada naskah strategi komunikasi promosinya, sehingga ke depan diharapkan ada penelitian lanjutan yang mengupas masalah ini melalui pendekatan teori komunikasil.

\section{DAFTAR PUSTAKA}

Agustin, Meli. 2014. Analisis Retorika Pada Iklan Vespa Berbahasa Jerman. Makalah NonSeminar. Fakultas IImu Pengetahuan Budaya, Program Studi Sastra Jerman, Universitas Indonesia

Barthes, Roland. 1984. Image - Music - Text. New York: Hill and Wang

Foss, S.K .2004. Rhetorical Critism: Exploration and Practice. Waveland Pr.Inc

Hutapea, Oktavianus Djoka. 2015. Retorika Visual Dalam Karya Fotografi Di Instagram (Analisis Pada 30 jenis Foto Di Instagram). Skripsi. Jurusan IImu Komunikasi Fakultas IImu Sosial Dan IImu Politik Universitas Brawijaya. Malang

Kurniawan, Hafid. 2015. Efektivitas media Sosial Instagram Sebagai Media promosi Batik Solo "Inasinul". Skripsi. Departemen Sains Komunikasi dan Pengembangan Masyarakat, Fakultas Ekologi Manusia. Institut Pertanian Bogor

Moriarty, S.E. 2011. Advertising: Jakarta. Prenanda Media Grup

Ratna, Nyoman Kutha. 2010. Metode Penelitian, Kajian budaya dan ilmu sosial humaniora pada umumnya. Yogyakarta: Pustaka Pelajar

Sobur, Alex. 2006. Semiotika Komunikasi, Bandung: Remaja Rosdakarya

Spradley. J.P. 1997. Metode Etnografi. Yogyakarta: Tiara Wacana 
Tinarbuko, Sumbo. 2009. Semiotika Komunikasi Visual Yogyakarta: Jalasutra.

Wijaya, Bergas Adhi. 2016. Analisis Retorika Visual Pada Iklan A Mild Versi Manimal. Skripsi. Jurusan IImu Komunikasi Fakultas IImu Sosial Dan IImu Politik Universitas Brawijaya. Malang

\section{Sumber Internet:}

BNI46. 2019, Banyak Promo Nonton dari BNI nih!, dilihat 12 Agustus 2019, < https://www.instagram.com/p/Bt0cUm9Ag63/

Kemp, Simon. 2019, Digital 2019: Clobal Internet Use Accelerates, dilihat 12 Agustus 2019, <https://wearesocial.com/blog/2019/01/digital-2019global-internet-use-accelerates>. 